\title{
Is there an association between convergence insufficiency and refractive errors?
}

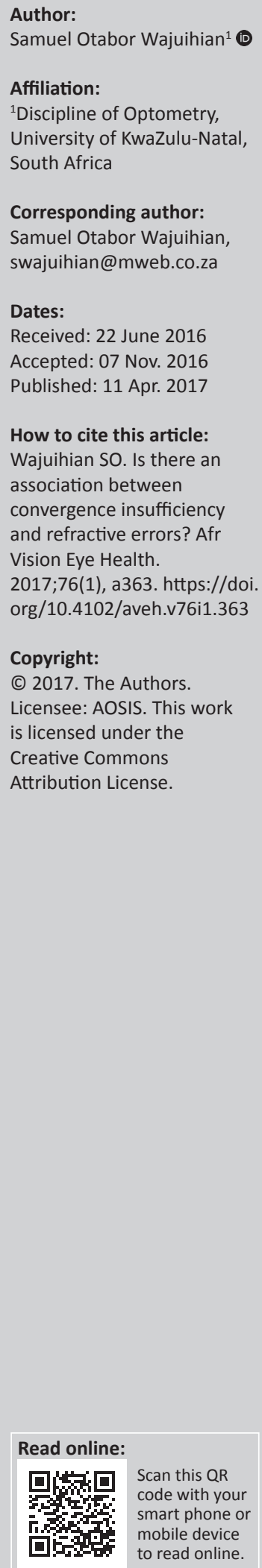

Background: Refractive errors and convergence insufficiency play major roles in reading efficiency. Uncorrected refractive errors are a primary cause of binocular anomalies, including convergence insufficiency. Symptoms of asthenopia in both refractive and binocular vision anomalies are similar. Despite the relationships that exist between them, the extent of association between refractive errors and convergence insufficiency has not been studied extensively.

Aim: The aim of this study was to determine the prevalence of convergence insufficiency and refractive errors and investigate their associations with gender and age in a sample of high school children.

Methods: The study design was cross-sectional and comprised data from 1056 African high school students aged 13-18 years, who were randomly selected from 13 high schools in uMhlathuze municipality in the province of KwaZulu-Natal, South Africa. In the final sample, $403(38 \%)$ were males and $653(62 \%)$ were females. The participants' mean age and standard deviation were $15.89 \pm 1.58$ years and median age was 16 years. Refractive errors, heterophoria, near point of convergence, fusional vergences and accommodative functions were evaluated.

Results: Prevalences for convergence insufficiency were as follows: low suspect $12.4 \%$ (confidence interval, [CI] 10.2-14.4), high suspect 6.3\% (CI, 5.0-7.9), definite 4.6\% (CI, 3.4-5.9), and pseudo-convergence insufficiency $2.1 \%$ (CI, 1.2-3.0). Refractive errors were: hyperopia $6.8 \%$ (CI, 5.3-8.4), myopia 6.0\% (CI, 4.6-7.5), astigmatism 2.3\% (CI, 1.8-3.2), anisometropia $1.3 \%(\mathrm{CI}, 0.7-2.0)$ and emmetropia $86.2 \%(\mathrm{CI}, 85.1-89.1)$. There were no significant associations between convergence insufficiency and gender $(p=0.32)$, age $(p=0.38)$, grade levels $(p=0.99)$ or refractive errors $(p=0.08)$.

Conclusion: The prevalence of clinically significant convergence insufficiency and refractive errors was low in this sample of black high school students in South Africa, and there was no significant correlation between them.

\section{Introduction}

'Vergence' is the simultaneous movement of the eyes in opposite directions to obtain or maintain single binocular vision. ${ }^{1,2}$ In vergence anomalies, the eyes are unable to fixate and stabilise a retinal image accurately, and the visual axes may move away from each other (divergence) or move towards each other (convergence). ${ }^{2,3}$ Convergence insufficiency $(\mathrm{CI})$ is a non-strabismic vergence anomaly characterised by the eyes' inability to accurately converge or sustain convergence for a considerable period of time when a near task is performed., 2,34 Refractive and accommodativevergence mechanisms are part of the visual efficiency system, and refractive errors (REs) play a dynamic role in the aetiology and treatment of binocular vision anomalies, including CI.,3 In school-aged children, functional CI is thought to result from a breakdown of the accommodativevergence mechanism. ${ }^{2,5}$ Such malfunction is triggered by the performance of prolonged visually demanding, near-centred tasks, such as reading, writing or computer-based work. ${ }^{2,4,5}$ Other risk factors for CI include uncorrected hyperopia, under-corrected myopia and poorly centred spectacle lenses. ${ }^{2,6,7}$ Children with refractive and accommodative-vergence anomalies could be at greater risk of reading and learning problems as well as anxiety, emotional and social problems. ${ }^{5,8}$

With emphasis on school-aged children between 6 and 18 years old, various studies have reported on the prevalence of $\mathrm{CI}^{9,10,11,12,13,14,15,16,17,18,19,20,21,22,23}$ and $\mathrm{REs}{ }^{24,25,26,27,28,29,30,31,32,33,34,35,36,37,38,39,40}$ and a few studies have reported on the relationship between CI and REs. ${ }^{41,42,43,44,45,46}$ Although REs are thought to be related to $\mathrm{CI},{ }^{41,42,43,44,45,46}$ the extent of their association has not been studied extensively. Therefore, the aim of this study was to determine the prevalence of CI and REs and investigate 
their associations with gender and age. Besides the inherent advantage in studying children in their learning environment, high school represents a period when changing academic demands may influence the distribution of refractive and accommodative-vergence functions and vice versa. This study enabled the research team to identify children in need of referral for intervention, and the findings will be relevant in optometric practice and research.

\section{Methods \\ Study design}

This report forms part of a larger cross-sectional study designed to quantify near-vision anomalies (refractive and accommodative-vergence) and its association with symptoms in order to develop strategies on how to identify and treat them. Appropriate consents were obtained from all the participants and the conduct of the study complied with the Declaration of Helsinki regarding research on human subjects. ${ }^{47}$ Data collection commenced only after ethical clearance was given by the Biomedical Research Ethics Committee of the University of KwaZulu-Natal, Durban, South Africa.

\section{Participants and study setting}

The target population was black high school students in uMhlathuze municipality. The sample comprised students selected from 13 out of a total of 60 high schools in the uMhlathuze municipality in the province of KwaZulu-Natal, South Africa. The original sample comprised 1211 children (481 males and 730 females) aged between 13 and 19 years. Participants were selected using stratified, multistage cluster random sampling (from the municipality to classroom levels). Students of African descent and of either gender were eligible to partake in the study. Based on the case history, participants were excluded from the study if they had any systemic conditions such as diabetes, hypertension and multiple sclerosis or if they were on any systemic medication. Children who were amblyopic and had suppression, strabismus, ocular diseases, nystagmus or vertical phorias were also excluded (for the vergence functions).

The sample size was calculated using the formula for a prevalence (descriptive) study ${ }^{48}$ :

$N=Z \alpha^{2} \times \frac{p(1-p)}{d^{2}}$

where $N=$ sample size, $Z_{\mathrm{a}}=1.96=(95 \%$ confidence interval $[\mathrm{CI}]), p=$ expected prevalence or proportion (in decimal point $)=$ estimate of $8.05 \%$ prevalence of refractive errors in a previous study ${ }^{20}$ and $d=$ precision or margin of error. ${ }^{48}$

The design effect of 1.5 gave a baseline sample size of 1065 participants; however, an additional 60 participants were added to compensate for possible non-response, missing data and sub-group analysis, thus making a minimum sample size of 1125 . This sample size was expected to give a power of 1.00 (i.e. 100\%) to detect significant differences between groups, for example, relating to gender or age.

\section{Materials and procedure}

Only students who consented were included in the study. A room was provided by the school principal at the school venue where the visual examinations were conducted. The purpose and procedures were thoroughly explained to each participant prior to the eye screening. To ensure that the participants understood all the instructions, trial testing was performed for complex tests, such as accommodative facility and fusional vergences. Validated optometric instrument and procedures were used as described in standard optometry books $^{2,6}$ and used in previous studies. ${ }^{9}, 10,11,12,13,14,15,16,17,18,19,20,21$ The test procedures and testing conditions across participants and study sites were standardised as far as possible, and an average of three test measurements were obtained for near tests. In the first station, trained personnel obtained case histories and participants' demographic details and visual acuities measurement. In the second station, measurements of the binocular functions were performed by an optometrist. To minimise bias, the assistant who collected the participants' demographic details worked independent of the optometrists. To eliminate potential inter-examiner variability, all tests were performed by one optometrist who was experienced in performing the techniques but not familiar with the classification criteria used in the study. All vision testing was performed between 8:30 and 13:30 and over a period of 1 year between March 2013 and May 2014. The following tests were performed. ${ }^{2,6}$

\section{Preliminary tests}

The preliminary tests included visual acuity (VA), which was assessed for each eye using the Logarithm of Minimum Angle of Resolution (LogMAR) chart (Precision Vision, Illinois, USA) at both distance $(6 \mathrm{~m})$ and near $(0.4 \mathrm{~m})$. Ocular health status was evaluated using a direct ophthalmoscope. Suppression was evaluated at near using the Worth-4-dot test (Bernell Corporation, Mishawaka, Inc., USA). ${ }^{2,6}$ The unilateral cover test was first performed to rule out strabismus. Stereoacuity was assessed using the Randot stereo test (Vision Assessment Corporation, USA) and ocular motility was evaluated using the Broad $\mathrm{H}$ test. 2,6 Non-cycloplegic refractive errors were evaluated objectively using an autorefractor (MRK/3100; Huvitz) and subjectively using the phoropter. ${ }^{2,6}$ As cycloplegia was not used, latent hyperopia was screened for using a 2D lens.

\section{Vergence tests}

The near point of convergence (NPC) was measured using the Royal Air Force (RAF) rule with a vertical line target, which was moved slowly towards the child. ${ }^{49}$ The break point was recorded for analysis when the child reported diplopia or at a point where the eye diverges. ${ }^{49}$ Possible cases of suppression were screened for using the Worth-4-dot test. In cases in which the subjects did not report diplopia, the point when the eye diverges was recorded. Distance and near 
heterophoria were evaluated by the von Graefe technique in a specially designed phoropter tripod using a single 20/30 Snellen letter target. ${ }^{2,6}$ Fusional vergences (positive and negative) were measured using a horizontal prism bar (Gulden B-16 horizontal prism bars; Gulden Ophthalmics, Elkins Park, PA, USA) while the patient fixated a hand-held fixation target (Gulden fixation Stick \#15302) with a single column of letters which correspond to a near VA of 20/30 equivalent at a distance of $40 \mathrm{~cm} .^{2,6}$ Accommodative functions including amplitude, response, facility and relative were also assessed, ${ }^{2,6}$ and the children identified with anomalies were referred accordingly.

For the single sign criteria (negative fusional vergence, or NPC; exophoria; and positive fusional vergence, or PFV) applied to define CI (Table 1), definitions were classified according to the criteria by Bade et al. ${ }^{50}$ For secondary outcome variables (which are not the direct focus of this article), accommodative insufficiency (AI) was defined as (1) reduced amplitude of accommodation (using the Hofstetter's formula), (2) high lag values (>0.75 D) on MEM retinoscopy and/or (3) reduced monocular $\mathrm{AF}(<6 \mathrm{cpm})$ with $-2 \mathrm{D}$ lens. ${ }^{16}$ Convergence excess (CE) was defined as (two out of three signs) (1) esophoria at near, $\geq 2 \mathrm{pd}$, (2) reduced negative fusional vergence (NFV) at near $<8 / 16 / 7$ for blur/break/ recovery or (3) high MEM $(\geq+0.75)$ (which may show high lag). Fusional vergence dysfunction (FVD) was defined as (1) reduced fusional vergence ranges (positive and negative fusion vergences), (2) normal phoria and (3) minimal refractive errors. ${ }^{2}$ Spherical equivalent refraction was applied only to estimate REs prevalence which would facilitate comparison with previous studies. To define the prevalence of astigmatism and in relation to $\mathrm{CI}$, absolute values of cylinder power were used.

\section{Data analysis}

The Statistical Package for Social Sciences (SPSS) Version 21 was used, and descriptive statistics included means, standard deviations and medians. The Kolmogorov-Smirnov test was used to assess the normality of data. Chi-squared tests were performed to analyse differences in proportions for categorical variables among groups, and the Kruskal-Wallis equality-of-population rank non-parametric test was used to compare differences in means between groups. Distributions of variables were presented using tables and proportions, and corresponding 95\% confidence intervals were presented with prevalence. A significance level of $<0.05$ was considered significant.

Convergence insufficiency was defined using the Convergence Insufficiency and Reading Study (CIRS) group's criteria (Table 1). ${ }^{10,11,13}$ The classification for refractive errors was based on criteria used in a previous study. ${ }^{51}$ Astigmatism was presented in minus cylinder notation, defined as $\leq|-0.75 \mathrm{D}|$ and sub-classified as: low (from $-0.25 \mathrm{D}$ to $-0.50 \mathrm{D})$, moderate (from $-0.75 \mathrm{D}$ to $-2 \mathrm{D}$ ) and high $(>-2 \mathrm{D})$. Hyperopia was defined as $\geq 0.50$ and sub-classified as: low (from $0.50 \mathrm{D}$ to $2.0 \mathrm{D}$ ), moderate (from $2.25 \mathrm{D}$ to $4.00 \mathrm{D}$ ) and high ( $\geq 4.25 \mathrm{D})$. Myopia was defined as $\leq|-0.50 \mathrm{D}|$ and subclassified as: low (from $-0.5 \mathrm{D}$ to $-3.0 \mathrm{D}$ ), moderate (from -3.25 $\mathrm{D}$ to $-6.0 \mathrm{D}$ ) and high as $\geq|-6.25 \mathrm{D}|$. Emmetropia was defined as $0.25 \mathrm{D}$ or less spherical equivalent refraction, while

\begin{tabular}{|c|c|c|}
\hline Signs & Convergence types & Criteria \\
\hline Multiple signs & $\begin{array}{l}\text { Convergence insufficiency clinical signs: } \\
\text { - Exophoria at near } \\
\text { - Exophoria at near } \geq 4 \text { pd greater than far } \\
\text { - Insufficient fusional vergence defined as either (1) fails Sheard's criterion or (2) poor PFV at near } \\
\leq 12 \text { pd. BO to blur or } \leq 15 \text { pd BO break. Poor BO break was used for insufficient PFV criteria. } \\
\text { - Receded } \mathrm{NPC} \geq 7.5 \mathrm{~cm} \text { break or } \geq 10.5 \mathrm{~cm} \text { recovery } \\
\text { Diagnostic system of the } \mathrm{Cl} \text { clinical signs: } \\
\text { - Low suspect } \mathrm{Cl} \\
\text { - High suspect } \mathrm{Cl} \\
\text { - Definite } \mathrm{Cl} \\
\text { - Pseudo-convergence insufficiency }\end{array}$ & $\begin{array}{l}- \\
- \\
- \\
\text { Exophoria } \\
\mathrm{NPC} \text { and exophoria } \\
\mathrm{NPC} \text {, exophoria and PFV } \\
\mathrm{Cl} \text { with Al }\end{array}$ \\
\hline Single clinical signs & $\begin{array}{l}\text { Near point of convergence (break): } \\
\text { - Mild } \\
\text { - Moderate } \\
\text { - Severe } \\
\text { Near exophoria: } \\
\text { - Orthophoria } \\
\text { - Mild } \\
\text { - Moderate } \\
\text { - Severe } \\
\text { Positive fusional vergence: } \\
\text { - Mild } \\
\text { - Moderate } \\
\text { - Severe } \\
\text { - Failed Sheard's criterion } \\
\text { - Passed Sheard's criterion }\end{array}$ & $\begin{array}{l}6 \text { to }<9 \\
9 \text { to }<12 \\
\geq 12 \\
0 \\
1-7 \\
8 \text { to }<13 \\
\geq 13 \\
\geq 15 \\
>7 \text { to }<15 \\
\leq 7 \\
<2 \times \text { mean near exo } \\
\geq 2 \times \text { mean near exo }\end{array}$ \\
\hline
\end{tabular}

pd, prism dioptre; PFV, positive fusional vergence; $\mathrm{BO}$, Base out; NPC, near point of convergence; $\mathrm{Cl}$, convergence insufficiency; $\mathrm{Al}$, accommodative insufficiency. 
TABLE 2: Descriptive statistics for visual acuity (in LogMAR), refractive and vergence parameters.

\begin{tabular}{|c|c|c|c|c|c|c|c|c|c|}
\hline Parameters & Mean & s.d. & Median & Min & Max & 1st quartile & 3rd quartile & Skewness & Kurtosis \\
\hline Visual acuity (right eye) & 0.05 & 0.13 & 0.00 & 0.00 & 1.00 & 0.00 & 0.00 & 3.79 & 16.63 \\
\hline Right eye sphere (D) & -0.01 & 0.35 & 0.00 & -6.00 & 2.00 & 0.00 & 0.00 & -6.22 & 76.19 \\
\hline Right eye cylinder (D) & -0.07 & 0.24 & 0.00 & -5.00 & 0.00 & 0.00 & 0.00 & -8.22 & 111.63 \\
\hline Spherical equivalent REs (D) & -0.03 & 0.38 & 0.00 & -5.50 & 1.75 & 0.00 & 0.00 & -5.65 & 155.00 \\
\hline \multicolumn{10}{|l|}{$\mathrm{NPC}(\mathrm{cm})$} \\
\hline Break & 6.89 & 2.89 & 6.00 & 5.00 & 38.00 & 6.00 & 7.00 & 6.11 & 48.39 \\
\hline \multicolumn{10}{|l|}{ Exophoria (pd) } \\
\hline Far & 0.33 & 1.18 & 0.00 & 0.00 & 12.00 & 0.00 & 0.00 & 5.67 & 42.84 \\
\hline Near & 2.47 & 3.36 & 1.00 & 0.00 & 18.00 & 0.00 & 4.00 & 1.67 & 5.70 \\
\hline Diff - far and near & 2.14 & 3.33 & 0.00 & -12.00 & 18.00 & 0.00 & 3.00 & 1.41 & 5.71 \\
\hline \multicolumn{10}{|l|}{$\operatorname{PFV}(p d)$} \\
\hline Break & 25.38 & 9.16 & 25.00 & 2.00 & 45.00 & 20.00 & 30.00 & 0.09 & 2.59 \\
\hline Recovery & 17.50 & 6.78 & 18.00 & 0.00 & 40.00 & 14.00 & 20.00 & 0.35 & 4.46 \\
\hline
\end{tabular}

REs, refractive errors; NPC, near point of convergence; PFV, positive fusional vergence; Min, minimum; Max, maximum.

anisometropia was defined as a difference of $>0.75$ or greater between right eye and left eye spheres.

\section{Results}

\section{Sample characteristics}

Of the 1230 students invited to participate in the study, 1211 students returned their consent forms, with three learners being excluded - one being diabetic, one having glaucoma and the other having corneal scars to because of trauma - and seven learners who had amblyopia were also excluded for the test on convergence insufficiency, leaving 1201 which gave a response rate of $95 \%$. A further 145 children aged 19 and above were excluded because of age factor. Thus, data were analysed for 1056 participants with a mean age of $15.89 \pm 1.58$ years and a median age of 16 years. Of the participants, $403(38 \%)$ were males and $653(62 \%)$ were females. The sample comprised $781(73.96 \%)$ students from grades 8-10 (lower grade level) and 275 students (26.07\%) from grades 11 and 12 (higher grade level). Table 2 shows the descriptive statistics for the right eye acuities, REs, NPC, exophoria and PFV. Given the moderate positive correlation between the left and right eyes spherical equivalent $(r=0.64$, $p=0.001$ ), only the results for the right eye are included here.

\section{Convergence insufficiency and refractive errors}

The prevalence estimates for CI using both the single sign (NPC, exophoria, PFV and Sheard's criterion) and multiple sign criteria (using the CIRS group) are indicated in Table 3. Low suspect CI was the most prevalent, whereas pseudoconvergence insufficiency (PCI) was the least prevalent. The chi-squared test showed that there was no significant association between $\mathrm{CI}$ and gender $(p=0.32)$, age $(p=0.38)$ or grade levels $(p=0.99)$. Prevalence for other vergence anomalies included the following: CE was found in 62 out of 1056 participants (5.9\%, CI: $4.5 \%-7.3 \%$ ), while FVD was found in 37 out of 1056 participants (3.5\%, CI: $2.4 \%-4.6 \%$ ). AI was found in 53 out of 1056 participants $(4.4 \%$, CI: $3.3 \%-5.6 \%)$. Hyperopia was the most frequent refractive error in $\mathrm{CI}$ followed by anisometropia and emmetropia while myopia and astigmatism were least frequent (Table 4), while the
TABLE 3: Prevalence of convergence insufficiency using single and multiple signs criteria.

\begin{tabular}{|c|c|c|c|c|}
\hline \multirow[t]{2}{*}{ Signs } & \multirow{2}{*}{$\begin{array}{l}\text { Convergence insufficiency } \\
\text { types }\end{array}$} & \multicolumn{2}{|c|}{ Prevalence } & \multirow[t]{2}{*}{$95 \% \mathrm{Cl}$ range } \\
\hline & & $n$ & $\%$ & \\
\hline \multirow{6}{*}{$\begin{array}{l}\text { Multiple } \\
\text { signs }\end{array}$} & Low suspect & 131 & 12.4 & $10.2-14.4$ \\
\hline & High & 67 & 6.3 & $5.0-7.9$ \\
\hline & Definite & 49 & 4.6 & $3.4-5.9$ \\
\hline & Pseudo- $\mathrm{Cl}$ & 22 & 2.1 & $1.2-3.0$ \\
\hline & $\mathrm{No} C l$ & 1034 & 97.9 & $97.0-98.8$ \\
\hline & Total & 1056 & 100.0 & $100.0-100.0$ \\
\hline \multirow{14}{*}{$\begin{array}{l}\text { Single } \\
\text { sign }\end{array}$} & Near point of convergence (break): & & & \\
\hline & - Mild & 916 & 92.3 & $90.6-94.0$ \\
\hline & - Moderate & 33 & 3.3 & $2.2-4.4$ \\
\hline & - Severe & 43 & 4.3 & $3.0-5.6$ \\
\hline & Near exophoria: & & & \\
\hline & - Mild & 912 & 91.9 & $90.1-93.8$ \\
\hline & - Moderate & 68 & 6.9 & $5.1-8.6$ \\
\hline & - Severe & 12 & 1.2 & $0.6-2.0$ \\
\hline & Positive fusional vergence: & & & \\
\hline & - Mild & 932 & 88.3 & $86.1-90.2$ \\
\hline & - Moderate & 107 & 10.1 & $8.4-12.0$ \\
\hline & - Severe & 17 & 1.6 & $0.9-2.4$ \\
\hline & - Failed Sheard's criterion & 63 & 6.4 & $4.9-8.0$ \\
\hline & - Passed Sheard's criterion & 929 & 93.6 & - \\
\hline
\end{tabular}

$\mathrm{Cl}$, convergence insufficiency.

prevalence of amblyopia was $0.58 \%$ (CI: $0.48 \%-1.8 \%$ ). There was no significant association between CI and REs (Table 4).

In this study, the prevalence of CI and REs and their possible associations were investigated. The prevalence of low suspect CI was $12.4 \%$, high suspect $6.3 \%$, definite $4.6 \%$ and PCI $2.1 \%$, while the prevalence of REs was as follows: hyperopia $6.8 \%$ (mainly low $+0.50 \mathrm{DS}$ ), myopia $6.0 \%$, astigmatism $2.3 \%$ and anisometropia $1.3 \%$. To the best of my knowledge, this is the first study to report on the prevalence of REs as well as CI in predominantly black high school children in South Africa.

Convergence insufficiency is the most prevalent near point vergence anomaly in school-aged children. ${ }^{4,8}$ Given that age influences ocular characteristics, ${ }^{24,25}$ the focus was mainly on high school children, with an upper age limit of 18 years. This approach should guide to document prevalence trends in school children for epidemiological use. Compared with previous studies, the prevalence of low suspect CI (12.4\%) is 
TABLE 4: Association between refractive errors and convergence insufficiency.

\begin{tabular}{|c|c|c|c|c|c|c|c|c|c|c|c|}
\hline \multirow{2}{*}{$\begin{array}{l}\text { Refractive } \\
\text { errors }\end{array}$} & \multicolumn{2}{|c|}{ Prevalence } & \multirow{2}{*}{$\begin{array}{c}\text { Confidence } \\
\text { interval }\end{array}$} & \multicolumn{2}{|c|}{ REs prevalence in $\mathrm{Cl}$} & \multicolumn{3}{|c|}{ Association between REs and $\mathrm{Cl}$} & \multicolumn{2}{|c|}{$\mathrm{No} C \mathrm{l}$} & \multirow[t]{2}{*}{$p$} \\
\hline & $n$ & $\%$ & & $n$ & $\%$ & $\chi^{2}$ & $d f$ & $p$ & $n$ & $\%$ & \\
\hline Astigmatism & 25 & 2.3 & $1.8-3.20$ & 3 & 12.0 & 0.27 & 1 & 0.60 & 22 & 88.0 & 0.76 \\
\hline Low & 0 & 0.0 & - & - & - & - & - & - & - & - & - \\
\hline Moderate & 24 & 2.2 & - & - & - & - & - & - & 24 & 8.0 & - \\
\hline High & 1 & 0.0 & - & - & - & - & - & - & 1 & 0.1 & - \\
\hline Hyperopia & 72 & 6.8 & $5.3-8.4$ & 17 & 30.9 & 0.00 & 1 & 0.93 & 55 & 76.3 & 0.96 \\
\hline Moderate & 0 & 0.0 & - & - & - & - & - & - & 0 & 0.0 & - \\
\hline High & 0 & 0.0 & - & - & - & - & - & - & 0 & 0.0 & - \\
\hline Myopia & 63 & 6.0 & $4.6-7.5$ & 9 & 14.2 & 3.00 & 1 & 0.08 & 54 & 85.7 & 0.07 \\
\hline Low & 61 & 5.8 & - & - & - & - & - & - & 61 & 5.8 & - \\
\hline Moderate & 2 & 0.2 & - & - & - & - & - & - & 2 & 0.2 & - \\
\hline High & 0 & 0.0 & - & - & - & - & - & - & 0 & 0.0 & - \\
\hline Emmetropia & 910 & 86.2 & $85.1-89.1$ & 217 & 23.8 & 1.53 & 1 & 0.21 & 692 & 76.0 & 0.27 \\
\hline
\end{tabular}

Bold values indicate the main refractive errors and their prevalences.

$\mathrm{RES}$, refractive errors; $\mathrm{Cl}$, convergence insufficiency.

moderately high, although it is lower than that reported by some studies ${ }^{9,10}$ but higher than that reported by others. ${ }^{11,12}$ The prevalence of high suspect CI (6.3\%) is higher than that reported by Rouse et al. ${ }^{9}$ but lower than others. ${ }^{10,11}$ The prevalence of definite CI (4.6) is comparable with that of Rouse et al.'s studies ${ }^{9,11}$ but lower than that reported by Rouse et al., ${ }^{10}$ whose data were derived from clinical samples and may be prone to selection bias. There was no significant influence of gender and age on CI and, similarly, a review ${ }^{8}$ found the influence of age and gender to be inconsistent.

PCI is a vergence anomaly which results from poor convergence because of insufficient accommodative ability, ${ }^{14,15}$ and symptoms of CI are amplified where CI coexists with $\mathrm{AI},{ }^{14,15}$ as $\mathrm{CI}$ on its own is not a very symptomatic anomaly. ${ }^{14,15}$ Consequently, PCI may create some therapeutic challenges as conventional treatment for CI does not completely resolve symptoms unless some accommodative therapy is initiated. ${ }^{14,15}$ Thus, the recognition of PCI as a unique anomaly will ensure appropriate diagnosis and treatment. The prevalence of PCI has not been reported extensively and here the prevalence of PCI $(2.2 \%)$ is lower than that reported by Marran et al. $(3.3 \%){ }^{14}$

Overall, the differences between findings from this study and others may be related to differences in study design such as whether samples were derived from non-clinical or clinical populations, the nature and extent of near tasks, as well as differences in measurement techniques and classification criteria. For example, the possible reason for a relatively high finding $(12.7 \%)$ for high suspect CI by Borsting et al. ${ }^{13}$ compared with our findings may be related to the use of a testing distance of $30 \mathrm{~cm}$ instead of $40 \mathrm{~cm}$ to measure near PFV. Moving the testing distance from $40 \mathrm{~cm}$ to $30 \mathrm{~cm}$ may have caused an approximate $5 \mathrm{pd}$ reduction in positive fusional range ${ }^{13}$ with a consequent increased failure rate on the PFV component. Another possible concern is that the mean NPC for high suspect CI which is $9.22 \pm 4.18$ was higher than reports from other studies which included Rouse et al. ${ }^{10}$ $(5.2 \mathrm{~cm} \pm 4.9 \mathrm{~cm})$, Rouse et al..$^{9}(4.8 \mathrm{~cm} \pm 3.6 \mathrm{~cm})$, Marran et al. $^{14}(6.17 \mathrm{~cm} \pm 4.14 \mathrm{~cm})$ and Borsting et al. ${ }^{13}(3.92 \mathrm{~cm} \pm$ $3.90 \mathrm{~cm}$ ). A possible explanation is that in this study, the NPC was measured using the RAF Rule which has been reported to yield relatively higher NPC break values than other techniques. ${ }^{49}$ Therefore, appropriate compensations should be considered when differences in technique are used. It may also be related to the fact that children in this study were older than in other studies.

Diagnostic criteria are important concerns in reports on CI. ${ }^{8,19}$ Single clinical signs such as receded NPC have traditionally been applied to define CI and remain relevant. ${ }^{12,21,22}$ In a survey by the College of Vision Development ${ }^{23}$ which aimed to determine how practitioners diagnosed CI, approximately $82 \%$ of optometrists diagnosed CI using receded NPC breaks only, 80.2\% applied the PFV (Sheard's criteria or Morgan's and OEP normative criteria) while $75.3 \%$ used near exophoria criterion, and Daum ${ }^{19}$ suggested that Sheard's criterion is an important clinical tool to diagnose CI. However, the NPC break criterion is the single clinical sign most commonly applied to diagnose CI. In this study, the frequency of NPC break $(>9 \mathrm{~cm})$ was $7.6 \%$ and Abdi et al. ${ }^{21}$ found $6 \%$ for NPC break $\geq 10 \mathrm{~cm}$. In the study by Junghans et al., ${ }^{12}$ the prevalence of NPC break defined as $7.5 \mathrm{~cm}$ was $11 \%$. Although single clinical signs have been considered inadequate to diagnose $\mathrm{CI}^{10,11}$ they may be relevant for a baseline diagnosis if a patient presents with obvious symptoms of asthenopia but without multiple clinical signs, refractive errors or other binocular anomalies.

In general, the prevalence of REs varies considerably according to region or ethnicity and age, which are major factors known to influence the prevalence of ocular characteristics including myopia. ${ }^{24,25}$ The prevalence of myopia in this study is higher than the estimates from other studies on African populations, for example, Naidoo et al. ${ }^{26}$ (2.9\% in South Africa) and both Kumah et al..$^{27}(3.2 \%)$ and Ovenseri-Ogbomo and $\operatorname{Assien}^{28}(1.7 \%)$ in Ghana. The differences in findings may be because those studies ${ }^{26,27,28}$ examined younger school children. Interestingly, the 
prevalence of myopia is more comparable with studies conducted on African populations where participants' age ranges $\left(13-18\right.$ years) are similar ${ }^{29,30}(5.6 \%-6.7 \%)$ to that in this study. The prevalence of myopia is known to increase with age..$^{25,31,32}$ For non-African populations, the prevalence of myopia in this study is remarkably lower than those from South East Asian populations which include Singapore $73.9 \%{ }^{33}$ and China $73.1 \%,{ }^{34}$ but notably lower in South Asian countries such as India $\left(7.4 \%{ }^{35} \text { and 5.6\% }\right)^{36}$ and Nepal (1.2\%). ${ }^{37}$ One reason for the marked difference might be that regardless of the geographic location of India, for example, genetic analysis revealed that Indians are not closely related to East Asians in terms of population genetics. ${ }^{31}$

Regarding age and myopia, most studies ${ }^{26,27}$ with an upper age limit of 15 years reported an increase in the prevalence of myopia. ${ }^{25,32}$ Naidoo et al. ${ }^{26}$ found that the prevalence of myopia increased with age, whereas in this study, age did not influence the prevalence of myopia. It is known that the prevalence of myopia progresses throughout school age and begins to stabilise towards late teens. ${ }^{25,32}$ The period in the mid-to-late teenage years when eye growth ceases ${ }^{25,32}$ corresponds roughly with the time of the cessation of general body growth, though there may be few cases of late-onset myopia and adult-onset myopia. ${ }^{25,32}$ Furthermore, both biometric and environmental factors influence the prevalence of myopia. ${ }^{31,52,53}$ The increase in axial length with age and in near work in high school students have been linked to an increased prevalence of late-onset myopia during high school. ${ }^{31,52,53}$

The prevalence of hyperopia is comparable with that of Ovenseri-Ogbomo and Assien in Ghana, ${ }^{28}$ who also did not apply cycloplegia. The findings from this study, however, contrast with Naidoo et al. ${ }^{26}$ and Kumah et al. ${ }^{27}$ both of whom applied cycloplegia and used a cut-off criteria of $2 \mathrm{D}$. The relatively higher findings in this study compared with these studies $^{26,27}$ may be related to a low criteria $(\geq 0.50)$ applied to define hyperopia. The low cut-off value was used as the focus of the entire study on near-vision anomalies and symptoms, and low positive lenses have been documented to alleviate symptoms of asthenopia and low accommodative anomalies. ${ }^{40}$ Furthermore, hyperopia is the refractive error that has been associated with poor reading and lowered academic performance in school-aged children. ${ }^{6}$

The prevalence of astigmatism (2.3\%) was lower than that reported by Naidoo et al. ${ }^{26}(9.2 \%)$ in South Africa and Kumah et al. ${ }^{27}(13.7 \%)$ in Ghana. The differences in findings among these studies may be related to age differences as well as the use of cycloplegia, although one study ${ }^{38}$ on high school children found cycloplegia not to influence the prevalence of astigmatism. Findings from this study are comparable with the 3\% prevalence estimates of Megbelayin et al. ${ }^{39}$ on Nigerian school children who also did not apply cycloplegia. Interestingly, the prevalence of astigmatism in this study is larger than that from most studies in the East African population $(0.1 \%$ and $1.1 \%))^{29,30}$ Most studies in Africa did not report on anisometropia and amblyopia although their prevalences are generally low, with anisometropia being between $1.4 \%$ and $15 \% .{ }^{26,27,28,29,30,31,32,33,34,35,36,37,38,39}$

\section{Association between convergence insufficiency and refractive errors}

The lack of significant association between CI and REs corroborates findings from other studies, ${ }^{2,41,42,43,45,46}$ whereas Gupta et al. ${ }^{54}$ found a significant association between CI and myopia. Regarding the distribution of REs in CI, findings are diverse. Compared with this study, Passmore and MacLean ${ }^{42}$ found that $52 \%$ of their CI sample was hyperopic, $34 \%$ myopic and 14\% emmetropic. Smith ${ }^{44}$ evaluated REs in patients with CI and found that $38 \%$ had low myopia, $57 \%$ were emmetropic and 5\% had hyperopia > $1 \mathrm{D}$. In contrast, Gupta et al. ${ }^{54}$ found myopia to be the most prevalent REs in CI. Junghans et al. ${ }^{45}$ found that the mean symptom scores for CI were significantly higher for students with hyperopia over $2 \mathrm{D}$ than for those with milder hyperopia, emmetropia, mild myopia or myopia over $-2 \mathrm{D}$.

In this study, REs were found in CI although a lack of association between REs and CI may be related to their low frequency and magnitude. However, the mechanism of the relation between REs and CI may be interpreted from various perspectives. The reduced accommodation demand in uncorrected myopia may result in insufficient accommodative convergence. $^{2,6}$ Some high hyperopes make no effort to accommodate; therefore, there is insufficient accommodative convergence, whereas full correction of hyperopia may increase the near exophoria which may strain the PFV leading to more symptoms. ${ }^{2,6}$ The study highlights the need for vision screening for CI and REs at school settings. Identifying children at risk, referral for diagnosis and commencing intervention before subjective symptoms develop is a way to prevent the consequences of such anomalies. ${ }^{55}$ Basic approaches to address CI and REs also involve providing appropriate spectacle correction as they improve VA, as well as accommodative-vergence functions. ${ }^{2,46}$ This study may be considered to have good internal and external validity given the aspects of the study design including random sampling, relatively large sample size and a high response rate. Furthermore, measures were taken to minimise bias and only one optometrist collected all the data, thereby eliminating potential inter-examiner variability. However, a limitation of the study is that cycloplegia was not used given the study setting, although latent hyperopia was screened for using a plus $2 \mathrm{D}$ lens.

\section{Conclusion}

Although both CI and REs were found in this sample of high school children, their prevalence was low and CI and REs were not significantly associated. These findings will enhance an understanding of CI and its association with REs. Screening for refractive and binocular anomalies in school children enables identification and referrals, which are important for diagnosis and treatment and promoting vision function and academic performance. 


\section{Acknowledgements}

I thank Dr Rekha Hansraj and Mr Percy Mashige for reviewing the manuscript.

\section{Competing interests}

The author declares that he has no financial or personal relationships that may have inappropriately influenced him in writing this article.

\section{References}

1. Von Noorden G, Campos EC. Binocular vision and ocular motility, theory and management of strabismus. 6th ed. Missouri: Mosby Inc; 2002.

2. Scheiman M, Wick B. Clinical management of binocular vision: Heterophoric, accommodative and eye movement disorders. 3rd ed. Philadelphia, PA: JB Lippincott; 2008.

3. Dwyer P. Clinical criteria for vergence accommodation dysfunction. Clin Exp Optom. 1991;74:112-119. https://doi.org/10.1111/j.1444-0938.1991. Exp Optom

4. Optometric clinical practice guidelines: Care of the patient with accommodative and vergence dysfunctions [homepage on the Internet]. American Optometric Association; 2006 [cited 2016 Jan 05]. Available from: http://www.aoa.org/ documents/CPG-20

5. Garzia R. The relationship between visual efficiency problems and learning. In: Scheiman $M$, Rouse $M$, editors. Optometric management of learning-related vision problems. 1st ed. St. Louis, MO: Mosby, 2006; p. 209-280.

6. Grosvenor T. Primary care optometry. 5th ed. Philadelphia, PA: Butterworth Heinemann Elsevier; 2007.

7. Jenkins RH. Characteristics and diagnosis of convergence insufficiency. Am Orthop J. 1999;49:7-11.

8. Wajuihian SO, Hansraj R. A review of non-strabismic accommodative-vergence anomalies in school-age children. Part 1: Vergence anomalies. Afr Vision Eye Health. 2015;74:1-10. https://doi.org/10.4102/aveh.v74i1.32

9. Rouse MW, Borsting E, Hyman L, Hussein M. Pilot study to evaluate convergence insufficiency in a school-aged population: Poster \# 54 (Bv-323). Optom Vis Sci. 1995;72:218. https://doi.org/10.1097/00006324-199512001-00353

10. Rouse MW, Hyman L, Hussein M. Frequency of convergence insufficiency in optometry clinic settings. Convergence Insufficiency and Reading Study (CIRS) Group. Optom Vis Sci. 1998;75:88-96. https://doi.org/10.1097/00006324199802000-00012

11. Rouse MW, Borsting E, Hyman L. Frequency of convergence insufficiency among fifth and sixth graders. The Convergence Insufficiency and Reading Study (CIRS) group. Optom Vis Sci. 1999;76:643-649. https://doi.org/10.1097/00006324199909000-00022

12. Junghans $B$, Keily $P$, Crewther DP, Crewther SG. Referral rates for a functional vision screening among a large cosmopolitan sample of Australian children Ophthalmic Physiol Opt. 2002;22:10-25. https://doi.org/10.1046/j.1475-1313. 2002.00010.x

13. Borsting E, Rouse MW, Deland PN, et al. Association of symptoms and convergence and accommodative insufficiency in school-age children. Optometry. 2003;74 25-34.

14. Marran LF, De Land PN, Nguyen AL. Accommodative insufficiency is the primary source of symptoms in children diagnosed with convergence insufficiency. primary source of symptoms in children diagnosed with convergence insufficiency.
Optom Visc Sci. 2006;83:E281-E189. https://doi.org/10.1097/01.opx.0000216097. Optom Vis

15. Mazow ML, France TD, Finkleman S, Frank J. Acute accommodative and convergence insufficiency. Trans Am Ophthalmol Soc. 1989;87:15-73.

16. Shin HS, Park SC, Park CM. Relationship between accommodative and vergence dysfunctions and academic achievement for primary school children. Ophthal Physiol Opt. 2009;29:615-624. https://doi.org/10.1111/j.1475-1313.2009.00684.x

17. Letourneau J, Ducic S. Prevalence of convergence insufficiency among elementary school children. Can J Optom 1988;50:194-197.

18. Scheiman M, Gallaway M, Coulter R, Reinstein F, Ciner E. Prevalence of vision and ocular disease conditions in a clinical pediatric population. J Am Optom Assoc. 1996;67:193-202.

19. Daum KM. Convergence insufficiency. Am J Optom Physiol Opt. 1984;61:16-22. https://doi.org/10.1097/00006324-198401000-00003

20. Wajuihian SO, Hansraj R. Near vision anomalies in Black high school children in Empangeni, South Africa: A pilot study. Afr Vis Eye Health. 2014;73:21-32.

21. Abdi S, Lennerstrand G, Pansell T, Rydberg A. Orthoptic findings and asthenopia in a population of Swedish schoolchildren aged 6 to 16 years. Strabismus 2008;16:47-55. https://doi.org/10.1080/09273970802020243

22. Letourneau J, Lapierre N, Lamont A. The relationship between convergence insufficiency and school achievement. Am J Optom Physiol Opt. 1979;56:18-22. https://doi.org/10.1097/00006324-197901000-00004

23. Rouse MW, Hyman L, Hussein M. How do we make the diagnosis of convergence insufficiency? Survey results. J Optom Vis Dev. 1997;28:91-97.
24. Kleinstein RN, Jones LA, Hullett S, et al. Refractive error and ethnicity in children. Arch Ophthalmol. 2003;121:1141-1147. https://doi.org/10.1001/archopht.121.8.1141

25. Logan NS, Gilmartin B. School vision screening, ages 5-16 years: The evidencebase for content, provision and efficacy. Ophthal Physiol Opt. 2004;24:481-492. https://doi.org/10.1111/j.1475-1313.2004.00247.x

26. Naidoo KS, Raghunandan A, Mashige KP, Govender P, Holden BA, Pokharel GP Refractive error and visual impairment in African children in South Africa. Invest Ophthalmol Vis Sci. 2003;44:3764-3770. https://doi.org/10.1167/iovs.03-0283

27. Kumah BD, Ebri A, Abdul-Kabir M, Abdul-Sadik A, Koomson N. Refractive error and visual impairment in private school children in Ghana Optom Vis Sci. 2013;90:1456-1461.

28. Ovenseri-Ogbomo GO, Assien R. Refractive error in school children in Agona Swedru, Ghana. S Afr Optom. 2010;69:86-90. https://doi.org/10.4102/aveh.v69i2.129

29. Njeru SN, Otieno SA, Karimurio J. Prevalence of significant refractive errors in high school students, Meru municipality, Kenya. East Afr. J Ophthalmol. 2009;15:40-45.

30. Wedner SH, Ross DA, Todd J, Anemona A, Balira R, Foster A. Myopia in secondary school students in Mwanza City, Tanzania: The need for a national screening programme. Br J Ophthalmol. 2002;86:1201-1206. https://doi.org/10.1136/ bjo.86.11.1200

31. Morgan I, Rose K. How genetic is school myopia? Prog Retin Eye Res. 2005;24:1-38. https://doi.org/10.1016/j.preteyeres.2004.06.004

32. Murthy G. Vision testing for refractive errors in school. Community Eye Health. 2000;13:3-5.

33. Quek TPL, Chua CG, Chong CS, Chong JH. Prevalence of refractive errors in teenage high school students in Singapore. Ophthal Physiol Opt. 2004;24:47-45. https:// doi.org/10.1046/j.1475-1313.2003.00166.x

34. He M, Zeng J, Liu Y, Xu J, Pokharel GP, Ellwein LB. Refractive error and visua impairment in urban children in southern China. Invest Ophthalmol Vis Sci. 2004;45:793-799. https://doi.org/10.1167/iovs.03-1051

35. Murthy GV, Gupta SK, Ellwein LB, Muñoz SR, Pokharel GP, Sanga L. Refractive error in children in an urban population in New Delhi. Invest Ophthalmol Vis Sci. 2002;43:623-631.

36. Dandona $R$, Dandona $L$, Srinivas $M$, et al. Refractive error in children in a rural population in India. Invest Ophthalmol Vis Sci. 2002;3:615-622.

37. Pokharel GP, Negrel AD, Munoz SR, et al. Refractive error study in children: Results from Mechi Zone, Nepal. Am J Ophthalmol. 2000;129:436-444. https://doi. org/10.1016/S0002-9394(99)00453-5

38. Fotouhi A, Hashemi H, Khabazkhoob M, Mohammad K. The prevalence of refractive errors among schoolchildren in Dezful, Iran. Br J Ophthalmol. 2007;91:287-292. https://doi.org/10.1136/bjo.2006.099937

39. Megbelayin, OE, Nkanga GD, Kalu A. Pattern of refractive astigmatism in Nigerian high schools. Sky J Med Med Sci. 2013;1:1-6.

40. O'Leary Cl, Evans BJW. Criteria for prescribing optometric interventions: Literature review and practitioner survey. Ophthal Physiol Opt. 2003;23:429-439. https:// doi.org/10.1046/j.1475-1313.2003.00137.x

41. Cooper J, Jamal N. Convergence insufficiency - A major review. Optometry. 2012; 83:137-158.

42. Passmore JW, MacLean F. Convergence insufficiency and its managements: An evaluation of 100 patients receiving a course of orthoptics. Am J Ophthalmol. 1957;43:448-456. https://doi.org/10.1016/0002-9394(57)92346-2

43. Davis A, Twelker JD, Miller JM, Harvey EM. The relation between convergence insufficiency and astigmatism. Invest Ophthal Vis Sci. 2015;56:532.

44. Smith A. Convergence deficiency: An occupational study. $\mathrm{Br}$ Orthoptic J. 1951;8:56-70.

45. Junghans BM, Azizoglu S, Barutchu S, Crewther SG. Asthenopic symptoms and refractive errors. Invest Ophthal Vis Sci. 2010;51:1712-1712.

46. Dwyer $P$, Wick B. The influence of refractive correction upon disorders of vergence and accommodation. Optom Vis Sci. 1995;72:224-232. https://doi.org/10.1097/ 00006324-199504000-00002

47. Declaration of Helsinki [homepage on the Internet]. [cited 2016 Apr 12] Available from: https://www.who.int/bulletin/archives

48. Hulley SB, Cummings SR, Browner WS, Grady DG, Newman TB. Designing clinical research. 3rd ed Philadelphia, PA: Lippincott; 2007.

49. Adler PM, Cregg M, Viollier AJ, Woodhouse M. Influence of target type and RAF rule on the measurement of near point of convergence. Ophthal Physiol Opt. 2007;27:22-30. https://doi.org/10.1111/j.1475-1313.2006.00418.x

50. Bade A, Boas M, Gallaway M, Mitchell L, Scheiman M, Kulp MT. Relationship between clinical signs and symptoms of convergence insufficiency. Optom Vis Sci. 2013;90:988-995. https://doi.org/10.1097/OPX.0000000000000012

51. Wajuihian SO. Frequency of asthenopia and its association with refractive errors. Afr Vision Eye Health. 2015;74:1-7. https://doi.org/10.4102/aveh.v74i1.293

52. Zadnik K, Frey GA. Refractive error in infants and children [homepage on the Internet]. [cited 2016 June 2]. Available from: https://www.nationalchildrensstudy. gov/about/organization/advisorycommittee/2003Sep/Pages/Other-Hypothesesgov/about/organiza

53. Jiang BC. Parameters of accommodative and vergence systems and the development of late-onset myopia. Invest Ophthal Vis Sci. 1995;36:1737-1742.

54. Gupta R, Sharma B, Anand R, Bawaria S, Dewada R. Association of asthenopia and convergence insufficiency in children with refractive error - A hospital based study. Int J Med Res Rev. 2013;1:222-227.

55. Dwyer $P$. The prevalence of vergence accommodation disorders in a school-age population. Clin Exp Optom. 1992;75:10-18. https://doi.org/10.1111/j.1444-0938. 1992.tb01010.x 